\title{
Crisis sistémica, actores y expectativas democráticas. Transformaciones institucionales y dependencia de la trayectoria en Ecuador (1979 - 2014)
}

\section{Systemic Crisis, Actors and Democratic Expectations. Institutional Transformations and Path Dependence in Ecuador (1979 - 2014)}

Diego Pérez

Recepción: 28 de Agosto de 2015 Aceptación: 4 de septiembre de 2015

\section{Resumen}

En este artículo se realiza una aproximación desde el institucionalismo histórico para ubicar algunos elementos centrales en la generación de crisis sistémicas en el espacio de relación Ejecutivo - partidos políticos operando en el Legislativo. A partir de ello, se introduce una breve agenda que permita reflexionar sobre la dimensión de las transformaciones sobre el sistema político en Ecuador a partir de la Constitución 2008.

Palabras clave: democracia, institucionalismo histórico, transformaciones, crisis, sistema político.

\begin{abstract}
This article presents an approach from an historical institutionalism's perspective and it is aimed at finding some key elements in the creation of systemic crises in the relationships between the Executive and the Legislative political parties. Based on it, a brief agenda is introduced, which enables us to think about the dimension of the transformations of the political system in Ecuador since the 2008's Ecuadorian Constitution is in force.
\end{abstract}

Keywords: Democracy, historical institutionalism, transformations, crisis, political system. 


\section{Introducción}

ste artículo es ambicioso en tanto intenta aproximarse a un extenso periodo de la historia ecuatoriana con la intención de comprender el funcionamiento de la democracia tras el retorno a la democracia en 1979. Las expectativas de la devolución del poder a los civiles, como en la mayoría de países de la región, se convirtieron paulatinamente en frustración ante la constatación de que la democracia no resolvía automáticamente los problemas de la cotidianidad, sino que, al contrario, generaba una serie de tensiones desconocidas bajo el gobierno militar: la conciliación de intereses divergentes por parte de los distintos actores del sistema político. Existe, en definitiva, interés por comprender el origen de las estructuras institucionales establecidas en el momento de la transición a la democracia (1979), que se ubica como el año cero del análisis y cuyas deficiencias permearán hasta el momento en que la Constitución de 2008 entra en vigencia.

Así, una primera preocupación para este texto está en el funcionamiento del sistema político, lo que supone delimitar el universo a un segmento que permita el trabajo de caracterización de las interacciones que se verifican en él. Estas páginas se concentran en la relación Ejecutivo - partidos políticos operando en el Legislativo. No obstante de ello, se hacen algunas menciones a la incidencia castrense en la construcción del sistema y la resolución de algunos momentos de conflicto; sin embargo, ello escapa al centro de interés en este documento ${ }^{1}$. A pesar de definir preliminarmente al sistema político post - transicional como presidencialista, se evidencia una peculiar relación Ejecutivo - Legislativo, que excede las dimensiones implícitas en la calificación del presi-

1 Es visible el rol de Fuerzas Armadas como un actor político determinante durante la transición y hasta la crisis política de 2005 - que terminó con la destitución del presidente Gutiérrez - porque se puede apreciar que éstas no se sometieron completamente a la estructura civil de control imaginada en el momento del retorno democrático. Siguiendo la dinámica de las transiciones pactadas, los militares aceptaron nominalmente tales mecanismos de control civil, pero las condiciones fueron predefinidas por tal institución previa a devolver el poder, de manera que se precautelara siempre la estabilidad castrense dentro del sistema y su capacidad para incidir sobre la toma de decisiones en algunos espacios políticos definidos como estratégicos. 
dencialismo, pues en el periodo 1996 - 2005, éste mostrará debilidades que serán aprovechadas por el Legislativo. A partir de allí se verifican algunas disfuncionalidades sistémicas: los dispositivos constitucionales y legales que le proveen al Ejecutivo de una intensa capacidad para marcar la agenda de política desde la que debería dominar el entorno, se muestran insuficientes ante una estrategia de sistemático bloqueo desde el Legislativo. La capacidad de este último para generar crisis y proponer al mismo tiempo sus vías de resolución, llevarán a que la posición de relevancia política se localice en el Congreso Nacional. Para los efectos prácticos, desde allí se determinarán el tipo de acciones admisibles por parte del Ejecutivo, y se negociarán los términos de relación entre sociedad y Estado. En definitiva, la privilegiada posición legislativa, convive con el presidencialismo consagrado constitucionalmente. El análisis de este tipo de tensiones configura el centro de preocupación para este documento.

La conformación legislativa, se debe tener en cuenta, será siempre fragmentada debido a la incapacidad para construir estructuras partidarias de alcance e impacto nacional, y en ello estará una de las principales razones para que la llegada de cualquier presidente, ocurra en ausencia de mayorías legislativas claras. De allí que necesite continuamente establecer acuerdos de gobierno con algunos de los partidos que operan en el sistema; estas alianzas Ejecutivo - Legislativo, sin embargo, implican una elevada competencia y la necesidad de que el Ejecutivo disponga de amplios recursos para mantener vigentes dichas alianzas. Por la naturaleza "existencial" de las alianzas, su mantenimiento es costoso porque demandan del Ejecutivo la posibilidad de incidir en determinados ámbitos de decisión; tarde o temprano, éste se verá tentado a romperla, con lo que el aliado originario pasará a la oposición. De allí que el Ejecutivo tendrá una necesidad más urgente de contar con un socio en el Legislativo, por lo que acudirá a otro (s) partido (s) que le brinde alguna sostenibilidad política para su gestión, pero la necesidad que tendrá de esta segunda alianza, justamente, la hará más costosa. Se repite el ciclo anterior, y, eventualmente llegará un momento en que el Ejecutivo 
debilitado será incapaz de establecer alianzas que sean numéricamente significativas, pero además, que tengan una prolongada expectativa de vida. Estas han sido las condiciones, se señala, que han precedido a los momentos de crisis, mismas que se han resuelto únicamente desde lo coyuntural, la salida del presidente, pero no desde lo estructural, la configuración del sistema de partidos o el fortalecimiento de la ciudadanía como actor político.

Finalmente, ante las crisis, las Fuerzas Armadas se activan para pacificar la convulsión social y avalar la resolución al conflicto político, dentro de los términos que el sistema de partidos haya establecido, y con el sucesor que éste haya considerado "seguro" para mantener la siguiente ronda de relaciones Ejecutivo - Legislativo ${ }^{2}$. Como se ha señalado, no se profundiza sobre las características de las intervenciones militares en el sistema, pero esta mención general explica la naturaleza general de su incidencia durante los periodos de crisis sistémica.

Se plantea el documento en tres secciones. La primera realiza una aproximación al institucionalismo histórico como la teoría que permitirá enmarcar la discusión que se realiza aquí. La segunda mira las deficiencias que a partir de tal construcción conceptual se resaltan en el caso ecuatoriano durante el periodo que va de 1979 a 2007. Para ello se utiliza el periodo 1979 - 1996 como el escenario general en que se plantean las reglas de juego en el sistema, luego, se introduce una sección intermedia en la que se enfatiza en la naturaleza de las "prerrogativas partidistas", cuyo rol y consecuencias se revisan con más detenimiento en el periodo de crisis sistémica (1996 - 2007). La tercera presenta algunas valoraciones de orden general sobre ciertos indicios que permitirían pensar en la existencia de transformaciones institucionales que romperían con la dependencia de la trayectoria institucional a partir del periodo $2007-2014$.

2 Más adelante, el texto analiza cómo los partidos van a proponer sucesiones que carecían de validez constitucional, pero que eran las únicas viables políticamente, para conseguir el consenso partidista que les permita existir. Fuerzas Armadas, avaló este tipo de soluciones con el fin de garantizar el mantenimiento de la "democracia" en el sistema. 


\section{Institucionalismo histórico: insertando la discusión en Ecuador}

La aproximación al funcionamiento del sistema político en los periodos señalados demanda de un marco teórico que permita una reflexión sobre las estructuras institucionales, y ubicar sus características. Al proponer esta aproximación sistémica se pretende ubicar interacciones que se verifican entre los actores seleccionados dentro del vasto universo de la política (partidos políticos operando en el Legislativo y Ejecutivo), y la manera cómo estos se influencian entre sí, al mismo sistema, y al entorno (Easton, 1982). La influencia - que se la leerá como una de las dimensiones "medibles" ${ }^{2}$ del poder, ocurre en dos sentidos: desde el impacto que los actores generan sobre el sistema al tomar decisiones que alteran las condiciones de funcionamiento de este, y, desde la manera cómo las circunstancias (permanentes o eventuales) del entorno obligan a que estos actores modifiquen la forma de relacionamiento al interior del sistema. A pesar de lo dicho, las instituciones tienden a la regularidad, son conservadoras, y las transformaciones son más bien inusuales. Restringiendo su definición, las instituciones se comprenden como

“...formal or informal procedures, routines, norms and conventions embedded in the organizational structure of the polity or political economy. They can range from the rules of a constitutional order or the standard operating procedures of a bureaucracy to the conventions governing trade union behavior or bank-firm relations. In general, historical institutionalists associate institutions with organizations and the rules or conventions promulgated by formal organization" (Hall \& Taylor, 1996: 938).

3 No se propone una medición cuantitativa de influencia de los actores en el sistema político; no obstante, bajo la determinación que hace Sartori (2000) sobre la relevancia de los partidos, se plantean como parámetros de tal dimensión del poder, la presencia permanente de dichos actores en los procesos de generación y resolución de los momentos de crisis sistémica que se observan en el país. 
Aquí se piensa a las instituciones en tres dimensiones, (1) decisional, que contiene las relaciones que derivan desde el Ejecutivo y desde la constitución como instrumento ordenador del sistema político; (2) deliberativa, que contiene la reflexión en torno a los partidos políticos operando como actores individuales, a los mismos en tanto parte de un sistema de partidos, $y$, al espacio desde el que tradicionalmente estos operan, el poder Legislativo; (3) la ciudadanía o sociedad, en tanto proveedora de legitimidad, que define una serie de formas de relacionamiento con las dos anteriores a través de grupos de presión y de acciones individuales. En la intersección de cada uno de estos ámbitos se podrán verificar relaciones de poder que responden a dinámicas históricas y a particulares agendas de cada uno de estos actores, que en la búsqueda de resultados puntuales arroja una forma de operación del sistema político.

La dimensión decisional refiere estrictamente al ámbito formal comprendido por las decisiones políticas adoptadas por el Ejecutivo, y el marco jurídico en que se desenvuelve el sistema político. El énfasis en el Ejecutivo guarda relación con la constatación del carácter fundamentalmente presidencialista del sistema, como se explicó previamente. Se debe resaltar que el postulado del institucionalismo ubica el concepto de la dependencia de la trayectoria ("path dependency") como la constatación de la reticencia al cambio que tienen las instituciones. Ello se da por razones eminentemente prácticas, pues en tanto las instituciones buscan ser mecanismos de optimización de información en el relacionamiento social, no tienen sentido reinventar el tipo de relación entre actores en cada ocasión, por lo tanto, se prefiere reiterar en acciones, lo que en última instancia puede llevar a pensar en las instituciones como organizaciones conservadoras con poca flexibilidad y deseo por insertar cambios en la citada trayectoria (James, 2009; Steinmo, 2008; Immergut, 2005; Thelen, 1999). Para el caso de análisis que se ha tomado, el Ejecutivo predomina sobre las otras instancias, opera como una válvula que permitirá/prohibirá la introducción de transformaciones en las formas de relacionamiento entre actores. Por otra parte, el marco jurídico del Estado, contemplado solo en su vertiente constitucional, 
se constituye en la medida de la situación institucional, en tanto esta tiende a derivarse del orden de fuerzas existentes en un momento político, y, desde este se pueden estructurar las condiciones bajo las que opera el mismo sistema. Así, la capacidad de incidencia del Ejecutivo sobre éste es central para comprender la razón por la que cada refundación nacional implica la promulgación de una nueva constitución que busca optimizar la posición del Ejecutivo, hecho que se verifica bajo las constituciones de 1979, 1998 y 2008.

Sobre la dimensión deliberativa, la referencia es a los espacios de representación política, que se encargarán de agregar demandas y transformarlas en decisiones políticas. Los partidos políticos son el actor principal en esta dimensión, pero es fundamental un ejercicio de profundización en torno a la categoría puesto que tienen que pensarse desde las dimensiones sistémica, la individual, y como actores en el subsistema del Legislativo. Por un lado, el sistema de partidos relaciona a sus partes y los lleva al desarrollo de dinámicas de cooperación y competencia para promover la adopción, incidir o bloquear decisiones (Sartori, 2000; Bowler, 2000; Strøm, 2000; Mair, 1997; Panebianco, 1990). A pesar de las individualidades intrínsecas a su naturaleza, los sistemas de partidos tienden a promover algunas actividades comunes a los intereses de sus miembros, mismas que generalmente van a tono con sus pretensiones de permanencia en el sistema, como en el caso de la cartelización o la adopción de mecanismos expansivos de captura de votos (catch - all party system) (Mair, 1997; Kirchheimer, 1980). Como actores individuales, presumiblemente dentro de espectros temporales extensos ${ }^{4}$ en los que procurarán su subsistencia como actores dentro

4 Es importante enfatizar aquí que si bien se considera que los partidos existen como instituciones que pretenden perdurar en el tiempo, la evidencia sobre Ecuador muestra un registro dubitativo en ese sentido. Freidenberg (2003) al analizar la historia reciente de los partidos en el país señala como hay un grupo "duro" de partidos cuya participación es consistente por lo menos desde el retorno a la democracia en 1979, pero a este lo rodea una suerte de cinturón de organizaciones que hacen entradas y salidas coyunturales del sistema. No obstante tal constatación, en el periodo escogido se ha verificado el surgimiento de tres organizaciones políticas (PRIAN, PSP y AP) que han operado en procura de mantenerse como partidos relevantes dentro del sistema. Un factor innegable es el de la movilidad de ciertas figuras en los partidos, que estando en la inmediata posición 
del sistema partidario, así como procurarán su predominio/influencia sobre el sistema político al competir por posicionar a individuos afines a sus agendas en diversas instituciones estatales, por mantener algún tipo de vinculación particular con la ciudadanía abanderando propuestas de ley o acciones concretas de apoyo o rechazo al gobierno en los intermedios de las competencias electorales, y, por mantener una agenda que les permita influir sobre aquella del Ejecutivo y sobre la predominante en el Legislativo. En el subsistema Legislativo los partidos tienen su natural espacio de operación, desde el que se verifica una particular relación con el líder Ejecutivo, misma que incluye pero no agota la operación partidaria en la búsqueda de sus objetivos desde el espacio al que la formalidad constitucional provee de legitimidad como el interlocutor por naturaleza de las demandas ciudadanas.

Para terminar se plantea una dimensión en la que se consideran las instituciones como producto de la vinculación entre ciudadanía y Estado a través de sus tomadores de decisiones. Los funcionarios electos para el Ejecutivo y Legislativo, así como los partidos, no compilan la totalidad de las demandas ciudadanas, y en el exclusivo ámbito de la relación Ejecutivo - Legislativo existen mecanismos informales de presión e influencia decisional en los que se verifica la presencia de la ciudadanía. El problema que surge con esta categoría es la amplitud de participantes a los que evoca su concepto, por lo que, y en reconocimiento de las limitaciones de este trabajo, solamente se menciona aquí la existencia de grupos de presión, en tanto se reconoce en ellos alguna estructura organizativa, objetivos, mecanismos de procura de intereses y una capacidad de presión sobre la administración del Estado (Di Tella, 2011; Von Beyme, 1986; Meynaud, 1960).

de sucesión al liderazgo de los mismos, cuando son desplazados por alguna circunstancia, fundan su propia organización. Estas no obstante, suelen tener una muy debil capacidad de supervivencia y tienden a desaparecer tras el acto electoral que generalmente es el causante de su surgimiento (el caso del PUR de Sixto Durán Ballén puede ser un ejemplo emblemático de lo dicho). En cualquier caso, para el periodo escogido se observa una tendencia por parte de los partidos a mantener su presencia dentro del sistema. 
Al mirar las transformaciones institucionales de un sistema que aparentemente provee de amplias herramientas a los actores posicionados en el Ejecutivo para conseguirlas, se debe considerar que al mismo tiempo, tiene que lidiar con las limitaciones que surgen de la propia naturaleza de las instituciones que operando desde el Legislativo, ven en la transformación el germen del debilitamiento en su acción. La reiteración de ciertas características en la relación planteada permite sostener la pobreza de las opciones de transformación, elementos que debilitarán la estructura del propio sistema y que darán lugar, más adelante, a la transformación de las reglas de funcionamiento del sistema a través de la Constitución de 2008.

Este documento, entonces, presume que dentro del sistema político ecuatoriano existe:

- Una preeminencia nominal del Ejecutivo;

- Un sistema de partidos cerrado sobre sí mismo, que opera como un cartel (Kirchheimer, 1980), y tiene una extensa capacidad de afectar la manera en que se establecen las agendas políticas;

- Una dependencia simbólica y política de las acciones de fuerzas armadas que operan como el fiel de una balanza, restituyendo el equilibrio cuando los dos anteriores lo han alterado.

Tales condiciones son efectivas en el periodo previo a 2008, cuando la promulgación de una nueva constitución provee indicios de una reorganización del sistema político en torno a la democratización de la participación, la búsqueda de la ampliación de la representación, y la intención de revitalizar el vínculo entre ciudadanos y las instituciones estatales a través de disposiciones que pretenden la democratización partidaria. Por otra parte, el marco constitucional que restringía severamente la posibilidad de intervención militar demanda una valoración más matizada, puesto que al tiempo que la formalidad constitucional se ha mantenido, no han existido condiciones de crisis que permitan mirar la reacción castrense bajo este nuevo marco. 


\section{Deficiencias en el sistema político ecuatoriano (1979 - 2007)}

\section{Algunos antecedentes (1979 - 1996)}

Es necesaria una mirada breve a la manera como se construye el sistema político ecuatoriano durante la transición. Esta aproximación permitirá delimitar la naturaleza de la relación entre los actores que se analizan en esta investigación, y precisar aquellos elementos que se presumen como los propiciadores del periodo que, más adelante, se califica como de "crisis sistémica".

Es importante notar que en Ecuador, a contramano de otras experiencias militares latinoamericanas, la dictadura que gobierna en los periodos 1972 - 1976 y 1979 - es distante en los métodos aplicados con relación a los actores de izquierda que se aplicaron en el resto de la región. El régimen "nacionalista revolucionario" que se implementa en un primer momento tenía como eje central de la política estatal la administración del petróleo y el mejoramiento de las condiciones entre la clase media del país, que "contrastó con la agudización de los problemas y el deterioro de las condiciones de vida del estrato bajo, lo que dio lugar a una profundización de la brecha social entre clases" (Ojeda, 2013:126). El principal instrumento de política pública para este gobierno radica en el Plan Integral de Transformación y Desarrollo (1973 - 1977), en el que se busca la comunión entre la aproximación "nacionalista - revolucionaria" y una administración tecnocrática del Estado que fundamentalmente pensaba en garantizar sus capacidades reguladoras y reducir brechas sociales (Argones, 1983; Nieto, 1983; Pérez Enríquez, 2012). A partir de 1976 el Consejo Supremo de Gobierno, triunvirato que intensifica los costados tecnocráticos del anterior, da inicio a la transición política al diseñar el Plan de Reestructuración Jurídica del Estado. La implementación de este constituye una pieza fundamental en la posterior democratización porque (1) da cuenta de la imbricación y coordinación partidista - militar en el pacto que permite la transición, (2) visibiliza la fluida comunicación entre intereses 
económicos y políticos, y (3) explica la limitada incorporación de la sociedad civil, no mediada por algún tipo de organización, en tal proceso. En cuanto al primer elemento, las tres comisiones creadas, encargadas de canalizar la transición (una tenía como fin elaborar la propuesta de nueva constitución, otra debía proponer reformas a la Constitución de $1945^{5}$, y una tercera elaborar las leyes de elecciones, de partidos, y un Estatuto de Referéndum), estaban integradas por actores políticos vinculados a los partidos existentes ${ }^{6}$ (Herrera, 2007). Sobre la segunda, Liisa North constata que

"La transición de gobierno militar a "democrático" civil en Ecuador se llevó a cabo en una sociedad en la cual "grupos comerciales - financieros - industriales de comportamiento rentista, que surgieron o pertenecían a las clases terratenientes tradicionales, penetraron directamente en el aparto estatal" (Larrea y North 1997:927). Estaban acostumbrados a equiparar sus intereses privados con los intereses nacionales" [sic] (North, 2006: 92).

5 El mecanismo de transición adoptado tuvo un referéndum para escoger una nueva constitución o la de 1945 reformada, y a partir de tal selección, se convocó a elecciones generales. En 1978 tuvo lugar tal proceso, en el que se optó por la inédita.

6 En la primera estuvieron representados los partidos Izquierda Democrática (ID); Acción Revolucionaria Nacionalista Ecuatoriana (ARNE); Partido Nacional Guevarista (de corte populista); Partido Patriótico Popular (PPP); Democracia Cristiana (DC, que mantuvo dos representantes); dos independientes, y un representante de las Cámaras de la Producción y otro de la Confederación Ecuatoriana de Organizaciones Sindicales Libres (CEOSL, socialista). Para la segunda comisión: Partido Conservador Ecuatoriano (PCE, con dos representantes); Concentración de Fuerzas Populares (CFP, representado por Jaime Roldós Aguilera, quien ganaría la primera elección del retorno a la democracia); Partido Republicano Independiente Ecuatoriano (PRIE); Unión Democrática Popular (UDP, que se uniría más adelante con la Democracia Cristiana); Partido Socialista Ecuatoriano (PSE); Izquierda Democrática (ID); Federación Nacional de Campesinos; Asociación Ecuatoriana de Radiodifusores (AER); y, un independiente. La tercera comisión tuvo representación de: Democracia Cristiana (DC, con Oswaldo Hurtado Larrea, quien sería el primer vicepresidente tras la transición, y asumiría la presidencia a la muerte de Roldós); Partido Socialista Ecuatoriano (PSE, que eventualmente incrementaría su representación a tres, luego de la renuncia de los miembros de la Izquierda Democrática); Partido Social Cristiano (PSC, que por las mismas razones expuestas incrementaría su representación a dos); Partido Liberal; Acción Revolucionaria Nacionalista Ecuatoriana (ARNE); Sindicato de Choferes; Federación de Ingenieros; un representante de la "izquierda"; y dos Independientes. 
El entrecruzamiento de tales intereses se vuelve evidente, además, al regresar sobre la lista de los participantes en las comisiones, y además, en las particularidades de las discusiones prevalecientes en aquel momento.

El tercer planteamiento, la limitada incorporación de la sociedad civil en el proceso de transición, tiene que comprenderse en el marco de una contradicción. Como bien anota Isaacs, en los diálogos políticos en torno a la transición "...se invitó prácticamente a toda fuerza social y politica organizada" (Isaacs, 2003: 263-264), y ello otorgó una amplia legitimidad al proceso, que además se transfirió a los gestores del retorno, y a la expectativa que generó la democracia en sus primeros ańos. Este dato, sin embargo, contrasta con el sentido de participación ciudadana que se va a demandar con intensidad en los años noventa, particularmente con relación a las posibilidades de inclusión política en los procesos de toma de decisión del Estado. Como se argumenta más adelante, la configuración política que se evidencia en el proceso que canaliza la transición en el periodo 1976 - 1979, excluyó jurídicamente la participación sin vinculación partidista o sindical.

A partir de 1979 inicia de manera formal la democratización. En este marco se consolidan los actores partidistas que, como se detalla más adelante, van a predominar en el sistema político, operando como los mejores intermediarios entre ciudadanía y gobierno. El problema con tal presunción es que la naturaleza del sistema los llevará, más bien, a buscar a la ciudadanía solamente para cumplimentar el acto electoral, sin más vinculación ni responsabilidad que el formalismo democrático. La pretensión de "articulación institucional de la sociedad" (Verdesoto, 2014: 205) que genera tantas expectativas en los primeros ańos de la transición, perderá impulso conforme el sistema de partidos comience a consolidarse y a ocupar los espacios auto asignados al momento de negociar la transición. El proceso de consolidación democrático que continuó, generó una dinámica en la que se evidenciaron dos compartimientos que interactuaban únicamente bajo situaciones de crisis: fuerzas armadas y partidos políticos. 
En el periodo 1979 - 1996 concurren tres elementos que van a marcar la dinámica de funcionamiento de la política, y son además, los que sentarán las bases para el periodo de crisis objeto de esta investigación: la consolidación del sistema de partidos con una reticente apertura a la incorporación de nuevos actores, una sucesión de reformas estructurales del Estado determinadas por las demandas hechas por las instituciones financieras internacionales (IFIs), y un refortalecimiento de la ciudadanía como actor político a partir de los desencantos de la democracia. Esta transición, en términos prácticos, implicó que los partidos políticos y a las fuerzas armadas equivalgan a dos compartimentos que se pretenden impermeables entre sí, pero que inevitablemente actuarán cooperativamente bajo circunstancias especiales. Con el retorno democrático, fuerzas armadas pasan a ocuparse de sus misiones profesionales, dejando la política a los civiles (Bustamante, 1986; Varas, 1991; Vallejo, 1991).

\section{Prerrogativas partidistas}

Al plantear la existencia de dos niveles de funcionamiento prácticamente impermeables entre sí, se plantea que las instituciones que operan en cada una de ellas operaran el sistema con la finalidad de restringir los espacios de control y regulación por parte de terceros. En el ámbito militar cualquier tipo de control ciudadano o político es nominal, las posibilidades de autorregulación son maximizadas, y los sistemas de ascensos, educación castrense, planificación e incluso presupuesto, entre otros, tienden a extraerse de la esfera pública bajo la noción de las preeminencias estratégicas para el Estado. Al igual que sus pares latinoamericanos, para el caso de las Fuerzas Armadas ecuatorianas de la post transición es visible el hecho de que aseguraron su nueva posición en la democracia a través de “... derechos o privilegios adquiridos de manera formal o informal para ejercer un control efectivo sobre su institución sin interferencia de los civiles" (Olano, 2001: 45). El establecimiento de 
estos espacios clausurados y privilegiados, denominados por Alfred Stepan como prerrogativas militares ${ }^{7}$ (Stepan, 1988) ha garantizado desde entonces la posibilidad de intervención castrense en el desempeño de la política, avalando o censurando las acciones de los políticos civiles a cargo de la administración del Estado.

Extrapolando la tipología de Stepan sobre las prerrogativas militares, es plausible plantear la existencia de una serie de áreas que los partidos protegieron de la posibilidad del control ciudadano, en las que establecieron su control exclusivo a través del establecimiento legal de mecanismos de acceso, recambio y supervisión de la gestión, atados a la presunción de legitimidad que el partido tenía por representar a la ciudadanía, y con una fuerte vinculación a los resultados electorales que cada partido estuviere en posibilidad de acreditar. Así, se propone la existencia de prerrogativas partidistas a las disposiciones que garantizarían un vasto control sobre el Estado, a partir de los resultados electorales, con poca incidencia ciudadana sobre los resultados de su ejecución.

Esta categoría permite comprender la dinámica de funcionamiento partidista en el periodo de crisis sistémica, pues evidencia la progresión que hacen los partidos hacia el control de ámbitos decisionales que por definición no hubieran tenido que residir en los partidos, porque los desnaturalizaba y volvía cada vez menos responsables ${ }^{8}$ ante la ciudadanía, profundizando su distancia y concentrando todo esfuerzo político en la conquista o mantenimiento de tales ámbitos, tornando finalmente el ejercicio político en autorreferencial. Estas prerrogativas se observan en el control del sistema electoral, de los mecanismos de validación de la constitucionalidad, y de administración de la justicia.

7 Según Stepan, estas prerrogativas, aparte de las citadas, también incluirían: (1) un rol independiente en el sistema político por parte de los militares, (2) Posición de asesores y consejeros presidenciales exclusivos en cuestiones de seguridad y defensa, (3)Autonomía y control de los servicios de inteligencia, (4) Un papel activo en la administración de empresas del Estado, sea a través de posiciones en sus directorios o en el manejo ejecutivo de las mismas, (5)Mantenimiento de un fuero privativo sobre sus acciones, y, en el caso de Ecuador, estas incluirían también la garantía de amplios espacios de acción para misiones de desarrollo interno.

8 Planteado en el sentido inglés de "accountability", ser responsable ante la ciudadanía por los actos desarrollados desde la función pública. 
Brevemente, se debe señalar que el control del sistema electoral es clave porque garantiza mecanismos que van a asegurar el status quo acordado durante la transición, mismo que se va sofisticando con las sucesivas reformas constitucionales, con el fin de ampliar el espacio de intervención de los partidos sobre éste. El sistema electoral en Ecuador se construyó alrededor del Tribunal Supremo Electoral (TSE), que mantenía funciones para la convocatoria, preparación, realización de las elecciones y conteo de los votos, así como las de corte electoral (proclamando resultados, aprobando el acceso al cargo a los ganadores, resolviendo impugnaciones a las candidaturas y disputas en cuanto a la disconformidad con los resultados, así como instancia sancionadora). Se puede apreciar que esta institución contaba con la llave para la incorporación y mantenimiento de los actores en el sistema, y también, con una capacidad sancionadora. El control del acceso al sistema se complementaba con la disponibilidad de fondos cuyo objeto era garantizar condiciones apropiadas para que los partidos se institucionalicen y puedan competir bajo condiciones relativamente equitativas. Sin embargo, tales fondos fomentaron "el fortalecimiento de los partidos en función de su tamaño", que a su vez mantenía un correlato con el éxito electoral, con lo que finalmente "coarta[n] la consolidación de organizaciones emergentes, tanto por el apoyo proporcional a la votación obtenida, cuanto por la barrera de apoyo solamente a los partidos legalmente constituidos" (Verdesoto, Ardaya, \& Torres, 2004: 73).

Bajo la Constitución de 1998 se expandió esta incidencia al disponer que lo pasen a integrar aquellos partidos con el mejor desempeńo electoral. Adicionalmente, las autoridades del TSE mantenían una línea de responsabilidad política ante el Congreso Nacional, la institución en que residía su origen, por lo que una alteración en las fuerzas en su interior implicaba un reacomodo del TSE, con independencia del tiempo por el que nominalmente estaban designados.

En cuanto a los mecanismos de validación de la constitucionalidad, estos consisten en la institucionalidad que conformó el Tribunal de Garantías Constitucionales (denominado Tribunal Constitucional a partir 
de 1998). A este le competía la revisión y garantía de la constitucionalidad de las normas emitidas, lo que proveía un momento de cabildeo político, y bajo la Constitución de 1998 el TC expandió su capacidad de revisión de constitucionalidad a los actos de las autoridades, con lo que se pronunciará no solo sobre la ley, sino sobre normas de menor jerarquía, y, además, tendrá capacidad para dirimir los conflictos de competencia que pudieran surgir. Por su naturaleza, esta instancia se convierte en una suerte de válvula que opera por fuera del espacio de negociación Legislativo - Ejecutivo, con la capacidad de regular el flujo de proyectos de ley, o en el peor de los casos, los ritmos de tratamiento de la misma. La conformación de esta instancia y los mecanismos de designación de sus miembros sufre cambios apenas perceptibles en cuanto a las disposiciones constitucionales, y, a priori, ello haría suponer mayor estabilidad pero se observa que en cinco ocasiones durante el periodo analizado se produjeran cambios a su configuración (1997, 2001, 2003, 2004, 2005) ${ }^{9}$, respondiendo a las demandas surgidas de la coyuntura política y sin seguir los mecanismos legales dispuestos para producirlos (Basabe - Serrano, Pachano, \& Mejía, 2010). Se puede afirmar que esta instancia tiene un rol político definido, y sus miembros responden a directrices partidistas, como se observa en el análisis que realiza Basabe - Serrano (2008), existe una correlación entre la manera en que los magistrados emitían sus votos, con la auto - ubicación ideológica, y si bien este análisis comprende únicamente al TC de los periodos 1999 - 2001 y 2001 - 2003, estos son los magistrados que lograron mantenerse por más tiempo dentro del periodo analizado. $\mathrm{Su}$ inestabilidad, por otra parte confirma el planteamiento de la centralidad de esta institución en el armado político ecuatoriano de aquellos años, y la manera en cómo los partidos influían sobre ella.

9 Aunque queda por fuera del periodo de análisis de esta investigación, se debe mencionar que en 2007 se produce un cambio adicional en esta instancia, que es el que avalará la primera ronda de reformas introducidas por el presidente Correa, comenzando con el mecanismo de destitución de legisladores que se habían opuesto a la realización de una consulta popular que iniciaría el proceso hacia la constitución aprobada en 2008. 
Finalmente, uno de los más complejos espacios en el debate sobre las denominadas prerrogativas partidistas es de la administración de la justicia. La Corte Suprema de Justicia, como en cualquier sistema, se asumía independiente de la influencia de los otros en el momento de la transición. En la práctica, su dependencia del Ejecutivo y del Legislativo la convirtió en el símbolo de la extensión del poder de los partidos que habían logrado encaramarse a uno de los más importantes espacios de control dentro del Estado. La ilusión post transicional de un sistema de división de poderes y eficientes mecanismos de pesos y contrapesos, que consolidara un espíritu republicano y de mutua responsabilidad política para la administración del Estado (Huntington, 1968; Montesquieu, 2001), tuvo una vida sumamente corta. El problema de la independencia judicial se comienza a discernir por el costado de los mecanismos de designación de los jueces, que para el sistema de 1979 y las enmiendas de 1984 entregan tal capacidad al Congreso Nacional.

Si bien los méritos que los potenciales magistrados debían cumplir estaban claramente descritos en la constitución, no es menos cierto que al otorgar a una instancia eminentemente política la posibilidad de seleccionarlos, los resultados se politizaron. En teoría, este riesgo se contenía a través de las demandas técnicas para el cumplimiento de su misión; pero estas perdían relevancia ante la presión ejercida sobre la institución, sobre todo cuando el poder judicial tenía ante sí “....determinados casos que, debido al perfil de las partes o en razón de que son casos donde se discute el ejercicio del poder, resultan extraordinariamente relevantes para quienes gobiernan" (Pásara, 2014: 79). Bajo las características señaladas, el funcionamiento del sistema judicial tendía a parecerse menos a aquel pulido mecanismo de pesos y contrapesos, y más bien pasaba a ser un espacio susceptible de secuestro por los intereses partidistas. Si bien es cierto que resultaría iluso tornar apolítico un espacio de esta naturaleza, la pretensión si se puede ubicar en la garantía de idoneidad de los magistrados, y sobre todo, en la estructuración de un sistema que no opere en sumisión a quien detente el poder (op. Cit.), aunque éste sea quien lo haya designado. En 1993 se introducen 
varias reformas a la constitución, una de las cuales afectaba a la configuración de la Corte Suprema de Justicia (CSJ). Es importante profundizar sobre los mecanismos que genera el citado artículo 104 reformado, puesto que en él se observa el cercano control que los partidos tendrán sobre la designación, lo que conduce a, por lo menos, sospechar una profunda línea de sumisión judicial a los partidos, pues cada una de las posiciones surgiría como fruto de una intensa negociación. Existen tres elementos a destacar en el mecanismo citado:

1. Doble mediación política para la designación de magistrados, pues el pleno del Congreso Nacional tenía la obligación de conformar una comisión específica para el fin, y luego, con un voto favorable de las dos terceras partes de sus integrantes, elegir a los miembros de la CSJ.

2. Sobredimensionamiento del Legislativo, porque (a) adicionalmente al mecanismo anterior, el Legislativo podía solicitar la sustitución de nombres en las listas de candidatos presentados por el Ejecutivo y el judicial, ante el incumplimiento de requisitos, cuya calificación siempre podía ser sujeto de interpretación; y, (b) si bien se había establecido una repartición equitativa de candidaturas entre los tres poderes, en última instancia la constitución proveía al Congreso Nacional la posibilidad de nombrar un magistrado más que reemplazaría al que fuere designado presidente, conformándose de esa manera el número impar propio de un cuerpo colegiado de esta naturaleza.

3. Renovación parcial y reelección indefinida, fue la fórmula planteada, que ponía presión sobre el magistrado, llevándolo a no ser molesto para quien lo designaba. La norma disponía reglas para el recambio, pero el que exista en paralelo la opción de reelección indefinida generaba contradicciones que suponían la apertura de un nuevo espacio para negociar su interpretación.

4. Continuidad ante el vacío, puesto que ante la falta de decisión 
para cubrir las vacantes, el pleno de la CSJ nombraría un magistrado de manera temporal.

Bajo el marco de la Constitución de 1998 el intento por limitar la discrecionalidad al crear mecanismos más restrictivos tampoco produce resultados favorables para la estabilidad del sistema sino que, al contrario, al plantear jueces vitalicios y trasladar el sistema de selección originaria a una comisión dependiente del Consejo de la Judicatura se congeló un equilibrio partidista coyuntural y no resolvió el problema de las tensiones generadas en torno a la conformación de la CSJ. Si el número de cambios sobre la conformación de la Corte es un indicador de la incidencia partidista, la constatación de que entre 1996 y 2006 se realizaron tres cambios en momentos que coinciden con momentos de particular tensión o reorganización de las fuerzas en el sistema de partidos (1997, 2004 y 2005) ${ }^{10}$ (Basabe - Serrano, Pachano, \& Mejía, 2010).

Así, la naturaleza del sistema de partidos tendió al clientelismo y generó las condiciones para, progresivamente, ampliar su inserción en zonas claves para la administración de los recursos de la política. Controlando las instituciones jurídicas y la totalidad de los mecanismos de participación política, la actuación de los partidos incentivó a que el régimen democrático se configure alrededor de “...máquinas electorales articuladas por lealtades personales - e incluso familiares - a un líder" (Andrade, 2004: 24) que habían estado parcialmente inactivas en el periodo de la dictadura. La diferencia sustancial, sin embargo, fue el traslado de tales lealtades a nuevos actores, partidos, concebidos como canalizadores de los deseos ciudadanos, en tanto “...una organización, que pretende ser duradera y estable, que busca influir en el Estado, generalmente tratando de ubicar a sus representantes reconocidos en posiciones de gobierno, a través de la competencia electoral..." (Abal Medina (h), 2002: 38).

10 Desde 1979 y bajo el marco constitucional analizado se registran cambios en 1984, 1985, 1990, 1997, 2004, 2005. En 2009 bajo la más reciente constitución se hace una nueva designación de la Corte Nacional de Justicia. 
El periodo de crisis sistémica (1996 - 2007)

Cuando en 1996 se inicia el juicio político al vicepresidente Alberto Dahik, la fugaz alianza trazada entre el partido de gobierno (Partido Unidad Republicana, PUR ${ }^{11}$ ) con el PSC se había roto. Sin un apoyo claro en el Legislativo y con una agenda de reformas amplia, que incluía temas relacionados a la seguridad social y a la privatización de empresas públicas, el Ejecutivo estaba abocado a concertar apoyos a cualquier costo. La acusación que se presentó en contra de Dahik fue por haber hecho uso de fondos reservados de la Presidencia de la República (existentes para fines relacionados con la seguridad nacional) para "comprar" votos en el Legislativo. Curiosamente, no hubieron los votos necesarios para destituirlo, no obstante, pocos días después del hecho tuvo que salir del país por el inicio de un juicio penal en su contra por peculado.

El argumento que se presenta con relación a este caso, contiene los elementos que permitirán explicar la crisis sistémica en los posteriores gobiernos. Así, se plantea inicialmente que las causas de la debilidad del Ejecutivo ante la incapacidad final para proteger al vicepresidente están dadas por la estructura partidista que no podía garantizar un desenlace distinto del logrado. En el gobierno de Durán Ballén las posibilidades de negociación de la agenda política en el congreso iniciaron en 1992 “...con una modesta representación en el Congreso y alianzas extraparlamentarias con la Izquierda Democrática y la Democracia Popular, su estrategia fue compartir el poder con estos partidos y el opositor Social Cristiano" (Andrade, 2009b: 58-59). Tras las elecciones legislativas de medio término en 1994, la situación de la alianza PUR-PCE fue aún menos favorable puesto que:

11 Este partido fue el primero de una serie de partidos "nuevos" que en realidad operaban como vehículos electorales. En este caso el PUR surgió de una escisión del PSC, cuando el liderazgo de este se negó a candidatizar a Durán Ballén a la presidencia, poniendo en su lugar a Jaime Nebot, en un hecho que, además, ratificó el traslado del centro político del PSC a la costa, algo sobre lo que el partido había dado ya sus primeros pasos en la transición, y que se había ratificado con la presidencia de León Febres Cordero en 1984. 
- La presencia propia de la alianza pasó de 17 diputados (12 PUR, 5 PCE, sobre 77 escaños disponibles $)^{12}$ a 9 (7 PCE, 2 PUR, sobre 77 escaños disponibles $)^{13}$.

- Las exigencias del PSC se incrementan conforme avanza el gobierno, al tiempo que Dahik y el liderazgo del PSC se enfrentan cada vez con más virulencia (Andrade, 2009b; Mejía Acosta \& Polga-Hecimovich, 2011) ${ }^{14}$.

- Existían condiciones de alta movilización social cuya ebullición fue contenida en 1995 como consecuencia de la guerra con Perú, pero que tensionaba al sistema, como consecuencia de la incapacidad creciente del gobierno para aprobar legislación, y dado que aquella aprobada tenía limitadas posibilidades de conseguir amplios respaldos populares por su origen y naturaleza neoliberal.

Este escenario se resolvió, con la necesidad del Ejecutivo de pactar con el PRE para desactivar el juicio político, y rescindir para los últimos meses de gobierno de cualquier posibilidad de impulsar algún punto de agenda política que no fuera el traspaso del poder a quien ganara la elección de 1996 (Conaghan, 2003; 1996). Este hecho, sin embargo, marcó el sendero que transitarían las relaciones partidos - Ejecutivo a partir de 1997.

Cuando el 10 de agosto de 1996 Abdalá Bucaram recibe la Presidencia de manos de Duran Ballén, inicia un gobierno desenfadado, histriónico ${ }^{15}$ y desinstitucionalizante. En términos de la relación entre actores, la primera evidencia tiene que ver con la distribución del poder

12 El PSC tenía 21, PRE 15, ID 8, DP 5.

13 PSC 26, PRE 11, Movimiento Popular Democrático 8, ID 7, DP 6.

14 Andrade citando a Mejía Acosta y Polga Hemcimovich destaca que: "el PSC buscó acceso a recursos estatales, incluyendo asignaciones presupuestarias por sobre $\$ 100$ millones para las provincias que este partido controlaba; transferencias monetarias directas desde los fondos discrecionales del Ejecutivo hacia legisladores del PSC; cargos para este partido en la Corte Suprema de Justicia y el Tribunal Supremo Electoral" (op. Cit, p. 52.).

15 Las particularidades personales del líder no importan para esta investigación, no obstante, existe información que es en proporciones iguales divertida y preocupante sobre las particularidades de Bucaram en cuanto al manejo de su imagen y la administración política del Estado. 
Legislativo entre los dos grandes partidos de la costa, PSC $(31,71 \%)$ y PRE $(24,39)$. Ello de partida implicaba una situación de confrontación sistémica, pues sumando el 30,49\% de la representación, la tercera, cuarta y quinta fuerza eran DP, PK e ID respectivamente; mientras tanto, el $13 \%$ de la representación estaba dividida entre partidos de la más diversa naturaleza, con representaciones sumamente reducidas. La agenda de gobierno, en realidad, no se alejaba de las visiones predominantes en el manejo económico, planteando proyectos que garantizaran la estabilidad monetaria que enfrentaba una pronunciada devaluación e inflación, y en el de política internacional, donde incluso se mantuvo al ministro de relaciones exteriores de Duran Ballén. En el manejo de la política interna, en cambio, la administración fue errática, visceral y sobre todo permitió que el gran tema de preocupación con el que había terminado el gobierno anterior reviviera con dimensiones inusitadas: la corrupción.

Ello desencadena una movilización social en contra del gobierno que coincide con el desgaste que enfrentaba en el Legislativo. La confrontación de fuerzas legislativas se decantó, finalmente por provocar el bloqueo en tal espacio. Se debe anotar que el Presidente procuró acercarse al movimiento indígena ${ }^{16}$, mantuvo una relación cercana con el presidente del Congreso ${ }^{17}$ hasta pocos días antes de su caída, y no se debe olvidar que mantuvo la segunda mayoría legislativa. Nada de

16 En el gobierno de Bucaram se crea un ministerio para asuntos indígenas, sin embargo el contexto de su creación está salpicado de suspicacia por haber ocurrido en medio de una clara estrategia por romper a PK distanciándolo de sus bases indígenas en el oriente ecuatoriano, trasladando algunos recursos de poder a un dirigente local que había roto previamente con la directiva nacional.

17 La presidencia recayó en Fabián Alarcón, uno de los dos diputados que había logrado alcanzar escaños por el Frente Radical Alfarista (FRA), un partido populista serrano de difusa ideología de izquierda. En realidad Alarcón importa porque su trayectoria permite evidenciar las dinámicas informales de operación del sistema que se ha descrito en páginas previas. En 1994 presidió las comisiones de Fiscalización y la de Asuntos Judiciales del Congreso, la segunda, como se recordará, tenía un rol central en la designación de miembros de la Corte Suprema de Justicia; desde la primera, encabezó los procesos en contra de los ministros de Duran Ballén. En 1995 concertó los apoyos del PSC y PRE para alcanzar la presidencia del Congreso y oponerse al vicepresidente Dahik. En 1996, es reelecto como presidente del Congreso gracias a una alianza con el mismo PRE, pero ante el consenso mayoritario de los otros partidos, se suma a la oleada que pedía la destitución de Bucaram (CIDOB - Barcelona Centre for International Affairs, 2001). 
CRISIS SISTÉMICA, ACTORES Y EXPECTATIVAS DEMOCRÁTICAS. TRANSFORMACIONES INSTITUCIONALES Y DEPENDENCIA DE LA TRAYECTORIA EN ECUADOR (I979-20I4)

esto impidió que los partidos concitaran una sucesión de acciones que darían legalidad al procedimiento Legislativo que declaró "loco" al Presidente, y por lo tanto incapacitado mentalmente para ejercer el poder. Estas acciones conectaron con las demandas que se habían originado en diversos sectores de la población y que, principalmente, se habían organizado en torno a la Asamblea de la Ciudad, convocada por el alcalde de Quito, Jamil Mahuad, para demostrar su oposición al régimen (Burbano de Lara, 2009) y demandar su salida. Estas condiciones configuraron el "Pacto de la camioneta"18, que atravesó todo el sistema de partidos y finalmente canalizó la salida del presidente y la institución de un nuevo orden partidista que operaría bajo un guión similar durante las crisis de 2000 y 2005. En este punto es clave subrayar las incapacidades del Ejecutivo para contener la oleada opositora que se logró articular en (1) gobiernos locales, especialmente aquellos administrados por la DP, ID y PSC, que se encargaron de facilitar las movilizaciones de ciudadanos, (2) movimiento indígena, reeditando la estrategia adoptada en 1990 y 1992, bloqueando carreteras y marchando hacia Quito, (3) el Congreso Nacional, proveyendo la salida jurídica a la crisis, y, (4) las fuerzas armadas, avalando las decisiones tomadas en el ámbito político y garantizando el respaldo al nuevo gobernante.

En el interinazgo que sucede, dirigido por Fabián Alarcón ${ }^{19}$, se redacta una nueva constitución, la de 1998, que "pretendió subsanar las falencias de diseño institucional que comprometían su eficacia y legitimidad" (Echeverria, 2010: 115) que se habían advertido por lo menos desde las enmiendas que se introdujeron sobre la constitución de 1979

18 El nombre surge de la imagen captada por los medios en la Plaza de San Francisco, en Quito, hacia el final de las protestas cuando Bucaram ya salió del Palacio de Carondelet. En ella se observan a los principales líderes de los partidos que favorecieron la salida del presidente: Fabián Alarcón (FRA, que como presidente del Congreso asumiría la Presidencia de la República en medio de una interpretación antojadiza que impidió que la vicepresidenta de Bucaram lo suceda), Jamil Mahuad (DP, que sería presidente en el periodo siguiente), Jaime Nebot y Heinz Moeller (diputados, y dirigentes del PSC), y Rodrigo Borja (ID, ex Presidente).

19 Representante de un partido minoritario, el Frente Radical Alfarista, que logró ubicarse en las posiciones clave que facilitaron su llegada a tal posición. En un sentido constitucional estricto, no se preveía la figura del interinazgo, y la argumentación del Congreso en torno a la incapacidad mental de Bucaram era endeble desde la perspectiva jurídica y procedimental. 
durante el gobierno de Durán Ballén. Sus principales demandas giraban alrededor de recuperar capacidades de gobierno para el Ejecutivo, ampliar los ámbitos decisorios para los gobiernos locales y garantizar de mejor manera los derechos para los pueblos y nacionalidades del Ecuador. De estos temas, probablemente el último se podría interpretar como vinculado a demandas originadas en la ciudadanía.

La fase final de los gobiernos que se suceden entre 1996 y 1998 revela, primeramente, que el PSC adopta una estrategia expansiva consecuencia de la cual había logrado hacerse de una serie de mecanismos de presión que operaban en la Corte Suprema de Justicia (Mejía Acosta \& Polga-Hecimovich, 2011), en los gobiernos locales (Echeverría, 1997; Carrión, 1997) y sobre todo en el Legislativo, donde había logrado demostrar que era posible gobernar sin necesidad del desgaste de la labor en el Ejecutivo (Andrade, 2009a; Burbano de Lara, 2005). Segundo, en la sierra los partidos con más visibilidad en este primer proceso de recambio de liderazgo (ID y DP) se fortalecieron de cara a las elecciones de 1998 (Ver: Gráfico 1), y lograron disputar un espacio que se había perdido ante PK, quien a pesar del rol que tuvo en movilizar las bases indígenas por toda la sierra, motivando la movilización general, redujo su presencia en el siguiente Legislativo. 
Gráfico 1 .

Resultados comparados de tres elecciones (\%)

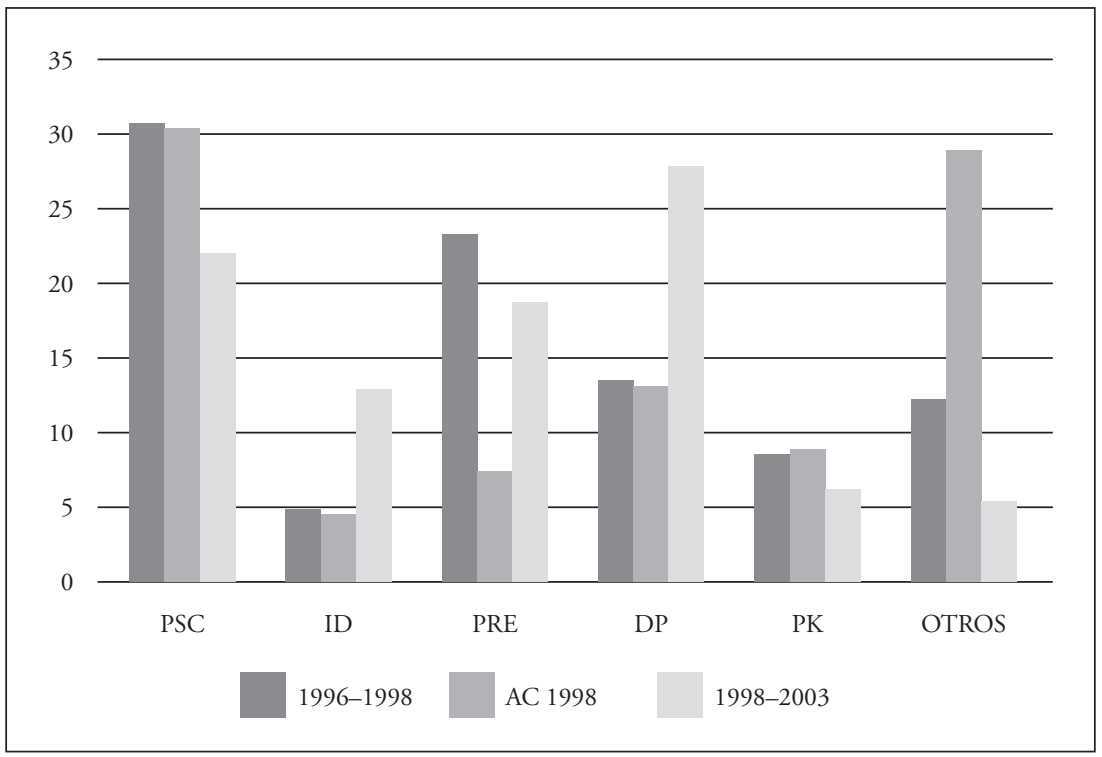

Fuente: (Tribunal Supremo Electoral, 1998; Freidenberg, 2008b)

Elaboración: del autor.

Tercero, esta pérdida de espacios en la representación, sin embargo, tiene un correlato en el reconocimiento "a los sujetos sociales que habían emergido en la década de los 90 -indígenas, mujeres, niños, jóvenes, afroecuatorianos- ampliando sus derechos específicos y reconociéndoles su capacidad de intervenir en la democracia y el Estado" (Ortiz, 2008: 59). Cuarto, estos grupos comienzan a configurar otro tipo de exigencias al Estado y ubicar las carencias en la representación partidista tradicional, procurando alternativas, ya que, como señala Ortiz (op. Cit), el marco constitucional construido respondía más a una coyuntura que a las preocupaciones sobre la democracia que se develaron con la crisis política de 1997. 
Bajo esta nueva constitución, Jamil Mahuad (DP) asume en 1998 el último gobierno de los partidos involucrados en la transición a la democracia. Enfocando esta reflexión sólo en el momento de crisis, se debe poner como antecedente su mayoría legislativa alcanzada mediante una alianza con el PSC que le garantizaba el 52\% de la representación congresal ${ }^{20}$. Este gobierno va a perder rápidamente su capital político y en el ańo 2000 se enfrenta a una crisis en la que:

“...coinciden en un mismo momento: aquellas que son fruto de cambios internos, tales como los de su sistema político, sus relaciones sociales y su economía entre otras, se yuxtaponen con los procesos propios de realineamiento del mundo contemporáneo. Estos, a su vez, conllevan grandes mutaciones en las condiciones internas, particularmente en lo que respecta al rol del Estado y al peso de los sectores relacionados con la exportación” (León, 2000: 87).

El recuento de la crisis es extenso, pero lo esencial a destacar es la acelerada pérdida de capacidad del gobierno de garantizar una mínima protección para la ciudadanía ${ }^{21}$. Mientras tanto, el PSC desde el Legislativo apostaba al desgaste del presidente desde el momento en que este planteó el congelamiento de depósitos, en marzo de 1999, rompiendo la alianza y bloqueando todas las iniciativas ejecutivas. Bajo tales condiciones, este gobierno afronta la necesidad de asegurar alianzas que

20 Aparte de las afinidades ideológicas que se habían labrado, tanto PSC como DP controlaban los gobiernos municipales de las dos ciudades más grandes del país, habían tenido una gestión favorable en tales instancias, y habían participado activamente en el derrocamiento de Bucaram, y en la reorganización del sistema político en la Asamblea Constituyente. De hecho, en tal espacio - presidido por Osvaldo Hurtado (DP), ex Presidente (1981-1984) y parte de una de las comisiones para la transición a la democracia - se negoció esta constitución que resultó “...una confusa combinación de expresión política y corporativa...” (Echeverría, 2011) en la que, más allá de los temas vinculados a la garantía de derechos y ciertos aspectos relacionados a la descentralización, se "manifestaba una hegemonía de las fuerzas sociales y económicas expresadas en los partidos de derecha y centro, que respiraban una atmósfera neoliberal bajo las banderas del libre mercado" (Ortiz, 2008).

21 El ejemplo más cruel de ello es la incautación de ahorros que se realiza a través del sistema bancario con el fin de garantizar la supervivencia de instituciones involucradas en el otorgamiento de créditos vinculados, una de las cuales, además, había financiado la campańa electoral del presidente. 
le doten de condiciones de gobernabilidad, lo que le empuja a la opción de conformar "mayorías móviles" que le permitan introducir una reforma tributaria (con ID) o aprobar el presupuesto (con PRE). En términos institucionales, esta dependencia del Ejecutivo frente a un solo actor en el Legislativo, se puede leer en términos de la perversidad de la estructura partidista construida, donde el otorgamiento ciudadano de la representación terminó significando el otorgamiento de amplios poderes para el control de un sinnúmero de instituciones del Estado, más allá de los presupuestos democráticos al momento de emitir el voto. Pero adicionalmente, en la dimensión partidaria con relación al Ejecutivo - hay que recordar que eventualmente la misma DP retiró el respaldo al presidente - terminó pasando una elevada factura en términos de la legitimidad de estos partidos como efectivos canales de vinculación con la ciudadanía. Ante el agotamiento de la credibilidad del Ejecutivo se concreta una amplia movilización social que tiene como planteamiento central la destitución del presidente, proceso que inicia en un golpe tramado desde la dirigencia indígena con apoyo de una facción militar, y que contenido en algún momento, da paso a una resolución partidista en el Legislativo, canalizada por los mismos partidos que previamente se habían aliado al gobierno (Mejía Acosta \& Polga-Hecimovich, 2011).

Tras el periodo de normalización del sistema post - golpe, bajo el gobierno de Gustavo Noboa, Lucio Gutiérrez alcanza la presidencia en las elecciones de $2002^{22}$. Gutiérrez tuvo éxito electoral en su primer intento porque en 2002, encarnaba la posibilidad de ruptura del pacto entre élites (Portugal Gouvea, 2006) que había dominado el escenario político ecuatoriano. Con su elección se habló de una derrota de los partidos tradicionales, sin embargo, y en la perspectiva histórica, su surgimiento califica más como una de las ocasiones en que se evidencia una situación de "talking back"23 de la que habla Conaghan (1996), cuando la sociedad se

22 Gutiérrez fue el coronel que condujo el golpe en contra de Mahuad en 2000. Indultado por Noboa, construye una alianza con Pachakutik, organización con la que gana la elección de 2002.

23 Comprendida como la reacción "insolente" de los electores ante las disfuncionalidades del sistema, eligiendo al completo opuesto de quien hubiera sido "aceptable" en caso de que tal sistema no hubiera entrado en crisis. 
ve obligada a ejercer su derecho (irónica situación que denota la debilidad institucional) al voto como forma de mantener viva esa fachada democrática. En términos electorales más amplios, sin embargo los dos partidos tradicionales de la Costa (PSC) y la Sierra (ID) arrasaron en votación en las provincias más pobladas, Guayas y Pichincha.

Los antecedentes para la crisis en este gobierno se pueden resumir en los siguientes hitos:

- Pacto con PSC y ruptura con PK durante los primeros seis meses de gobierno.

- Adopción de una agenda económica y fiscal que buscaba cumplir con las disposiciones de las IFIs.

- Pretensión de contener los focos de oposición a través de la construcción de organizaciones extra partidarias.

- Pretensión de reorganización de la CSJ (para lo cual rompió con PSC y se alió con PRE).

La rapidez con la que Gutiérrez alterna sus alianzas, así como su ductilidad ideológica, debilitó su base de apoyo. La pretensión de despolitización de la justicia se puede observar el error estratégico que cometió, pues afecta el feudo de su socio político, PSC. Como ya se ha relatado, las alianzas tienden a ser costosas bajo contextos en los que la necesidad de mantenerlas ha sido probada (Mejía Acosta \& Polga-Hecimovich, 2011; Mejía, 2003). Gutiérrez propugna una reorganización de la CSJ en 2005, misma que tenía como pieza central el retorno de Bucaram, exiliado en Panamá desde 1997. Las tensiones que se habían venido acumulando en el sistema encuentran en este hecho el pretexto perfecto para desplazarlo del poder, como efectivamente sucede el 20 de abril de 2005, tras una movilización ciudadana importante. El escenario fue, en el estilo de 1997, el Congreso Nacional, donde se conforma una mayoría parlamentaria que decide que este ha abandonado el cargo, y por lo tanto se da paso al vicepresidente, con quien se reinicia el sistema. 
Tras todos los sucesos relatados existen algunos componentes comunes a las crisis que se suscitan entre partidos y Ejecutivo. Se debe resaltar que esta relación ocurre en la dinámica de los sistemas, donde los actores no operan solos, y mantienen directa o indirectamente relaciones de doble vía (influyen y son influenciados) con todo su entorno (Luhman, 2013). El primero visible es la naturaleza territorial de los partidos políticos. Se emplea este término tanto en el sentido geográfico, puesto que los partidos ecuatorianos seleccionados tienden a representar específicamente a una región del país; pero también se sugiere tomarlo en el sentido más animal de protección de un espacio considerado vital. A veces las dos acepciones se cruzan en la actuación partidaria, y desde ella censuran la iniciativa que puede tener un líder. El segundo es realista. Cada acción dentro del sistema sucede con una intencionalidad y no se espera nada menos que la justa reacción ante estas. En ese sentido, las acciones procurarán la relevancia, el reconocimiento, la consolidación (Maquiavelo, 1987) del actor; tal visión se opone a una perspectiva estrictamente idealista - ideológica. El hecho es que, como se ha visto, los partidos actúan siempre atados a fines particulares. Tercero, el Ejecutivo es un punto más dentro del sistema, tiene que jugar por tales reglas, y debe asumir la presión a la que será sometido como consecuencia de ello. Como se ha observado, el Ejecutivo opera dentro de una doble dimensión, pues mientras constitucionalmente se le asignaron herramientas que optimizaran su posición, las prácticas institucionalizadas por el sistema de partidos - algunas formales, otras no - determinaron ámbitos ubicados por fuera de aquello que se podía reformar, en tanto hacía el espacio de prerrogativas partidistas.

\section{Indicios de transformación institucional (2007 - 2014)}

Las páginas precedentes intentan proveer una mirada sobre el periodo de crísis sistémica en el que se han identificado algunas regularidades en el funcionamiento del sistema y los elementos que detenían las preten- 
siones de cambio sustancial sobre este. Las condiciones que se verifican hasta el momento en que tiene lugar la elección de 2006 comienzan a cambiar aceleradamente en lo retórico. Durante la campaña de tal año, Rafael Correa plantea la reorganización del sistema político a través de la promulgación de una nueva constitución, actuación soberana del país en el manejo de la economía y las relaciones internacionales, reducción de las brechas sociales. Amparado en esta plataforma gana las elecciones presidenciales de 2006, pero carece completamente de representantes propios en el Legislativo, pues durante la campańa tomó la decisión de no presentar candidatos a tales funciones. Se colige de lo señalado en páginas previas, que ello implicaba carecer de incidencia, no solo legislativa, sino en el TSE, y TC, válvulas clave para facilitar el control sobre el sistema.

En un complejo contexto político, pero con un amplio apoyo de la ciudadanía, se convoca a una Asamblea Constituyente en la que logra una importante mayoría desde la que va a poder construir una Constitución que buscará modificar las deficiencias sistémicas causantes de las crisis descritas. Bajo este marco existen algunas características significativas. Así, en primer lugar se debe notar que tan pronto Alianza País comienza a operar en el sistema, logra establecerse como una fuerza mayoritaria que tiene, además, una capacidad de crecimiento pronunciado, basta nada más contrastar como, para la redacción de la constitución de 2008 y las sucesivas elecciones legislativas, este partido crece sistemáticamente en su representación teniendo un arranque en cero, pues carecía de candidatos, estructura y experiencia en el sistema (Ver: Gráfico 2). 


\section{Gráfico 2.}

Desempeño electoral Alianza País (Asamblea Constituyente y Asamblea Nacional)

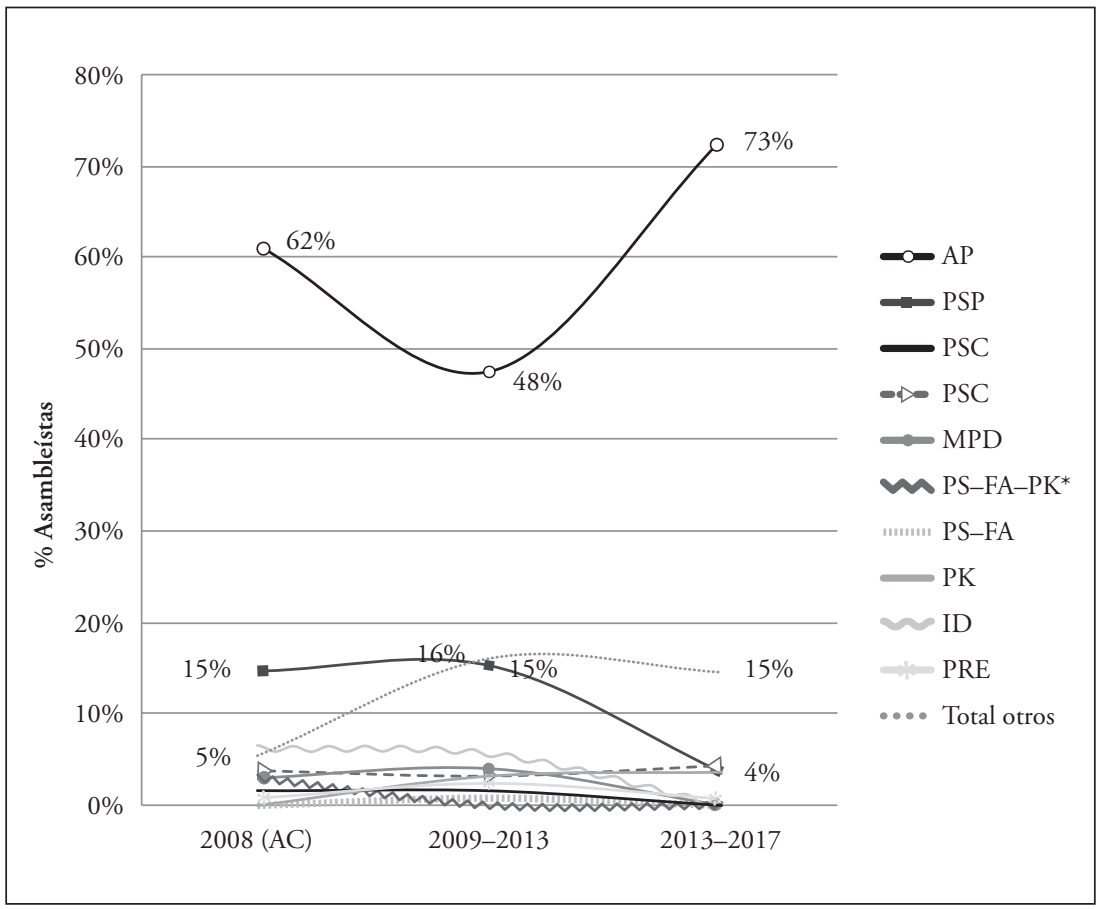

Fuente: (Consejo Nacional Electoral, 2015; The Carter Center , 2008; Pachano, 2010) Elaboración: del autor.

Como se observa, existe un pronunciado crecimiento de representación partidaria en un lapso breve de tiempo que permitió que la organización del presidente pasará del $62 \%$ en su primera participación frente al sistema de partidos tradicional, al 73\% de representación en el poder Legislativo en la última elección. Ello implicó una gran capacidad para implementar las transformaciones constitucionales, y, ya en funcionamiento de la Asamblea Nacional, una fortaleza particular para implementar las leyes que permitirían operativizar las transformaciones 
derivadas de la Constitución 2008. En esta primera línea de reflexión, es pertinente contrastar estas cifras con las que se han presentado antes en torno al desempeño electoral de los partidos tradicionales, lo que permite dimensionar el tipo de transformación que trae sobre el sistema la aparición de este nuevo competidor. Ello supone un traslado de las fuerzas partidarias hacia este nuevo actor que sustituirá, paulatinamente, a los actores tradicionales tanto en las elecciones de carácter nacional como en las locales (Consejo Nacional Electoral, 2015). A partir de los resultados destacados, se observa como los partidos "relevantes" en los periodos previos, pasarán a ocupar una posición de relativa irrelevancia en el contexto partidista, y ello supone, a la vez, que las capacidades de presión e influencia que habían construido en los ańos precedentes, se debilitarán sustancialmente ${ }^{24}$.

En segundo lugar, dentro de esta línea de reflexión, se debe considerar que los dispositivos presidencialistas que tenían una marcada tendencia in crescendo en todo el periodo democrático, bajo la actual estructura constitucional se profundizaron. Se mantiene la figura de colegislador para el presidente, así como, desde la práctica, se ha fortalecido su capacidad para la intervención en el proceso Legislativo. Pero además, la estructura constitucional del Estado ha permitido centralizar en el Ejecutivo una capacidad de regulación del sector público a través de mecanismos que han incrementado los ámbitos decisorios de los que este dispone. Bajo la pretensión del “...ensanchamiento de la base de derechos" que está en la base de la constitución 2008, "la viabilidad de esta propuesta consiste en la centralización política (hiperpresidencialismo), económica (planificación protagónica) y territorial (redefinición de competencias subnacionales); y en el engrosamiento de la base material del Estado (captación de excedente)" (Verdesoto, 2014: 388). En términos prácticos, los elementos que se han descrito en capítulos anteriores, en el contexto de fraccionamiento y descrédito partidista, han provocado que las condiciones de la competencia se

24 En 2015, la función legislativa está conformada por 137 asambleístas. De ellos, en la legislatura para el periodo 2013 - 2017, 100 pertenecen al movimiento de gobierno. 
polaricen entre los actores vinculados al líder Ejecutivo, y aquellos que con pocas posibilidades de acción, se oponen a él. Esta, no obstante, no es una ecuación de simple oposición - apoyo, sino que implicaría que las consecuencias de la mencionada personalización, debilitarían la fortaleza institucional del mismo sistema que se pretende construir con la constitución 2008. Tal afirmación, sin embargo, no podría ser confirmada o desechada sin mediar un periodo prudente para el análisis de la extensión de la transformación institucional que se ha iniciado. No obstante lo señalado, se puede apreciar lo siguiente:

- Existe un proceso de re - politización de la sociedad, en el que el debate político y la toma de posiciones sobre cuestiones de la actualidad ha recuperado importancia como consecuencia del posicionamiento en el debate público de una infinidad de temas relacionados con la construcción misma del Estado;

- El Estado ha recuperado su capacidad regulatoria, particularmente en los sectores sociales, de planificación y de administración de la economía;

- Los partidos políticos ya no constituyen el centro de bloqueo de los procesos de toma de decisiones, no obstante, ello no es consecuencia de una racionalización de sus actuaciones a través de mecanismos institucionalizados de transferencia de demandas, sino de un importante debilitamiento de su presencia y sus capacidades para representar demandas provenientes de la ciudadanía;

- Las fuerzas armadas no han tenido un rol decisorio sobre los momentos de tensión que ha afrontado el sistema ${ }^{25}$, y se han dis-

25 Existe un solo momento en que se verifica este tipo de tensión. El 30 de septiembre de 2010 tiene lugar una protesta policial relacionada con salarios y otros beneficios, a la que el presidente acude para explicar los alcances de la ley. Consecuencia de su presencia allí, es retenido por efectivos de esta institución y confinado al Hospital de la Policía, en el norte de Quito, en un secuestro que se prolongará hasta la noche de aquel día. Saldrá de allí gracias a una intervención militar que desarrolló un operativo de liberación, en medio de una confrontación armada con efectivos de la policía que pretendieron mantener al presidente en tal condición. 
puesto mecanismos de mediación política entre el líder Ejecutivo y las fuerzas armadas, de manera que estas rescindan de algunas de sus prerrogativas en torno al diseño y control de la política de defensa.

En esta línea, el sistema ha afrontado una suerte de ruptura, puesto que se han establecido nuevas condiciones de relacionamiento entre los actores, y se han procurado institucionalizar varios de sus espacios de funcionamiento. Si bien la distancia es todavía muy corta como para poder afirmar categóricamente la existencia de transformaciones institucionales que replanteen la dinámica de la relación líder Ejecutivo - partidos - fuerzas armadas, considero pertinente aventurar una afirmación en ese sentido, pues a pesar de un re - fortalecimiento de algunos de los actores tradicionales, ha existido una clara reubicación del polo de poder en el sistema de partidos que traería como escenario la consolidación del sistema que se establece desde 2008, con unos cuantos actores partidarios nuevos que recogen a varios individuos de las organizaciones anteriores, pero que además, incorporan a nuevos personajes. De todas maneras, queda pendiente una valoración de la operación de las instituciones, a la luz de la reflexión histórica que impone la reflexión institucional. No obstante, ante la situación de bloqueo que se retrató como estructural para el sistema político predominante antes de 2006, es posible pensar que de no haber aprovechado el caudal electoral inicial, las transformaciones desencadenadas, en cualquiera de los ámbitos que se consideren, hubieran probado ser un ejercicio fallido, debilitándose en la incapacidad para garantizar que las instituciones, por lo menos, afronten la alternativa de cambio. 
CRISIS SISTÉMICA, ACTORES Y EXPECTATIVAS DEMOCRÁTICAS. TRANSFORMACIONES INSTITUCIONALES Y DEPENDENCIA DE LA TRAYECTORIA EN ECUADOR (I979-20I4)

\section{Bibliografía}

Abal Medina, J. (2002). "Elementos teóricos para el análisis contemporáneo de los partidos políticos: un reordenamiento del campo semántico". En El asedio a la política. M. Cavarozzi, \& J., Abal Medina (h) (Edits.), Santa Fe: Homosapiens.

Andrade, P. (2004). ¿Populismos Renovados? Ecuador y Venezuela en perspectiva comparada. Quito: UASB.

Andrade, P. (2009a). Democracia y cambio politico en el Ecuador: Liberalismo, política de la cultura y reforma institucional. Quito: Universidad Andina Simón Bolívar - Corporación Editora Nacional.

Andrade, P. (2009b). La era neoliberal y el proyecto republicano. Quito: Universidad Andina Simón Bolivar - Corporación Editora Nacional. Basabe - Serrano, S. (2008). "Las preferencias ideológicas y políticas judiciales: un modelo actitudinal sobre el voto en el Tribunal Constitucional de Ecuador”. América Latina Hoy (49), 157-177.

Basabe - Serrano, S., Pachano, S., \& Mejía, A. (2010). "La democracia inconclusa: derechos fundamentales, instituciones políticas y rendimientos gubernamentales en Ecuador (1979 - 2008)". Revista de Ciencia Politica, 30 (1), 65-85.

Bowler, S. (2000). "Parties in legislatures: two competing explanations". En Parties without partisans. R. Dalton, \& M. Wattenberg (Edits.), (págs. 157-179). Oxford: Oxford University Press.

Burbano de Lara, F. (2005). "La transición política". En La transición española a la democracia. 25 años después - Un debate desde Ecuador. (págs. 47-53). Quito: FLACSO.

Burbano de Lara, F. (2009). "Quito y la caida de Bucaram. Discurso, identidad y representaciones”. En Quito, desarrollo para la gente. Metrópolis. Dinámicas. Actores. Indicadores. C. Jarrín (Ed.), (Tomo II) (págs. 63-102). Quito: Corporación Instituto de la Ciudad.

Bustamante, F. (1986). "Los paradigmas en el estudio del militarismo en América Latina". Documento de trabajo (320).

Carrión, F. (1997). "La ciudad acerca la política y la democracia a la 
gente: gobierno local y nuevos liderazgos". Íconos. Revista de ciencias sociales (3), 83-90.

Conaghan, C. (1996). "A deficit of Democratic Authenticity: Political Linkage and the Public in Andean Polities". Studies in Comparative International Development, 31 (3).

Conaghan, C. (2003). "Políticos versus Partidos: discordia y desunión en el sistema de partidos ecuatoriano”. En Antologia. Democracia, gobernabilidad y cultura politica. (págs. 219-260). Quito: FLACSO. Consejo Nacional Electoral. (2015). Atlas Electoral del Ecuador. 2009 2014. Quito: Consejo Nacional Electoral.

Constitución Politica de la República del Ecuador, 1979 Codificación 1984. (1984). Quito.

Constitución Politica de la República del Ecuador, 1979 Codificación 1993. (1993). Quito.

Constitución Politica de la República del Ecuador. (1979). Quito.

Constitución Politica de la República del Ecuador. (1998). Quito.

Di Tella, T. (2011). Sociología de los procesos politicos. De la movilización social a la organización politica. Buenos Aires: El Ateneo.

Easton, D. (1982). Esquema para el análisis politico. Buenos Aires: Amorrortu Editores.

Echeverría, J. (1997). La democracia bloqueada. Teoría y crisis del sistema politico ecuatoriano. Quito: Letras.

Echeverria, J. (2010). Complejización del campo político en la construcción democrática en el Ecuador. En Transiciones y rupturas. El Ecuador en la segunda mitad del siglo XX (págs. 76-113). Quito: FLACSO, Sede Quito.

Echeverría, J. (2011). "Cambios de paradigma en el desarrollo constitucional del Ecuador". En Justicia, soberania, democracia e integración en América. H. Rivadeira (Ed.), (págs. 113-120). Quito: UASB - Ediciones La Tierra.

Freidenberg, F. (2008b). "El sueño frustrado de la gobernabilidad: Instituciones, actores y política informal en Ecuador”. Documentos CIDOB. Serie América Latina (24), 3-116. 
Hall, P., \& Taylor, R. (1996). "Political Science and the Three New Institutionalisms”. Political Studies, 44 (5), 936-957.

Herrera, K. (2007). "Los tortuosos caminos de la democracia en el Ecuador". Visita del 23 de Julio de 2011, de Repositorio Digital FLACSO Andes. Disponible: http://hdl.handle.net/10469/1350

Huntington, S. (1968). Political Order in Changing Societies. New Haven: Yale University Press.

Immergut, E. M. (2005). "Historical-Institutionalism in Political Science and the Problem of Change". En Understanding Change. Models, Methodologies and Metaphors. A. Wimmer, \& R. Kössler (Edits.), (págs. 237-259). Houndmills, England: Palgrave Macmillan.

Isaacs, A. (2003). "Los problemas de consolidación democrática en Ecuador". En Democracia, gobernabilidad y cultura politica. F. Burbano de Lara (Ed.), (págs. 261-286). Quito: FLACSO, Sede Quito. James, S. C. (2009). "Historical institutionalism, political development and the presidency". En The Oxford Handbook of the American Presidency. G. C. Edwards III, \& W. G. Howell (Edits.), (págs. 51-84). New York: Oxford University Press.

Kirchheimer, O. (1980). "El camino hacia el partido de todo el mundo". En Teoría y sociología críticas de los partidos politicos. K. Lenk, \& F. Neumann (Edits.). Barcelona: Anagrama.

León, J. (2000). La crisis de un sistema político regionalizado en Ecuador. En La crisis Ecuatoriana: Sus bloqueos económicos, politicos y sociales. Quito: CEDIME.

Luhman, N. (2013). Introduction to systems theory. Malden: Polity Press. Mair, P. (1997). Party system change. Oxford: Clarendom Press.

Maquiavelo, N. (1987). Discursos sobre la primera década de Tito Livio. Madrid: Alianza Editorial.

Mejía Acosta, A., \& Polga-Hecimovich, J. (2011). "Soluciones parlamentarias a las crisis presidenciales en Ecuador". Revista Latinoamericana de politica comparada (4), 49-73.

Mejía, A. (2003). "Partidos políticos: el eslabón perdido de la representación”. En Democracia, gobernabilidad y cultura politica (págs. 
287-324). Quito: FLACSO, Sede Ecuador.

Meynaud, J. (1960). Les groupes de pression. Paris: Les Presses Universitaires de France.

Montesquieu, C. d. (2001). The spirit of laws. Ontario: Batoche Books. Nieto, V. (1983). Critica al plan integral de transformación y desarrollo 1973-1977. Guayaquil: Universidad de Guayaquil.

North, L. (2006). "Militares y Estado en Ecuador: ¿construcción militar y desmantelamiento civil?" Iconos, Revista de Ciencias Sociales (26), 85-95.

Ojeda, L. (2013). Planificación ecuatoriana. Visión retrospectiva. Quito: Instituto de Investigaciones - UNAP.

Olano, A. (2001). Las relaciones civico militares y la caída de la democracia en el Perí. n.d.: European Press Academic Publishing.

Pachano, S. (2010). "Ecuador: El nuevo sistema político en funcionamiento". Revista de Ciencia Política, 30 (2), 297-317.

Pachano, S. (2010). "Estado, ciudadanía y democracia". En Transiciones y rupturas. El Ecuador en la segunda mitad del siglo XX. F. Burbano de Lara (Ed.), (págs. 43-74). Quito: FLACSO, Sede Ecuador.

Panebianco, A. (1990). Modelos de Partido. Madrid: Alianza Editorial. Pérez Enríquez, D. (2012). "Liderazgo político y transformaciones institucionales. Revisar las transiciones con ocasión del bicentenario". En Reflexiones del Bicentenario de la Independencia de los Paises Iberoamericanos. J. Aponte (Ed.), (págs. 319-383). Bogotá: Ediciones Escuela Superior de Guerra.

Portugal Gouvea, C. (2006). "Presidencialismo y Corrupción en América Latina: un cuento de premisas equivocadas y percepciones disruptivas". En Poder Ejecutivo (págs. 253-278). Buenos Aires: SELA - Editores del Puerto.

Sartori, G. (2000). Partidos y sistemas de partidos. Madrid: Alianza Editorial.

Steinmo, S. (2008). "What is Historical Institutionalism?” En Approaches in the Social Sciences. D. Della Porta, \& M. Keating (Edits.), (págs. 150-178). Cambridge: Cambridge University Press. 
Stepan, A. (1988). Rethinking Military Politics: Brazil and the Southern Cone. Princeton: Princeton University Press.

Strom, K. (2000). "Parties at the core of government". En Parties without partisans. R. Dalton, \& M. Wattenberg (Edits.), (págs. 180203). Oxford: Oxford University Press.

Thelen, K. (1999). "Historical institutionalism in comparative politics”. Annual Review of Political Science, 2, 369-404.

Tribunal Supremo Electoral. (1998). Informe del Tribunal Supremo Electoral al Congreso Nacional. Informe, Tribunal Supremo Electoral, Quito.

Vallejo, M. (1991). Los roles de las Fuerzas Armadas ecuatorianas en el post - retorno: un acercamiento a su análisis. FLACSO, Sede Quito. Quito: FLACSO, Sede Quito.

Varas, A. (1991). "Las Relaciones Civil - Militares en la Democracia”. En América Latina, Militares y Sociedad. D. Kruijt, \& E. Torres - Rivas (Edits.),. San José: FLACSO.

Verdesoto, L. (2014). Los actores y la producción de la democracia y la politica en Ecuador. 1979 - 2011. Quito: Abya - Yala.

Verdesoto, L., Ardaya, G., \& Torres, A. L. (2004). "La subvención pública para las elecciones en Ecuador: elementos de interpretación de un subsidio potencialmente perverso". Revista Ciencias Sociales (21), 63-85.

Von Beyme, K. (1986). Los grupos de presión en la democracia. Buenos Aires: Editorial de Belgrano.

Weber, M. (2003). Parlamento y Gobierno en una Alemania reorganizada. En Obras Selectas. M. Weber, (págs. 255-400). Buenos Aires: Distal. 
Referencias electrónicas

Argones, N. (1983). La modernización del escenario político ecuatoriano 1968-1980 en un contexto de capitalismo tardio desarticulado. Repositorio Digital FLACSO Andes. Visita del 12 de Abril de 2009. Disponible en: http://hdl.handle.net/10469/371

Ortiz, S. (2008). "El contexto político de la Asamblea Constituyente en Ecuador”. Visita del 27 de Enero de 2015, de Instituto de investigación y debate sobre la gobernanza. Disponible en: http://www. institut-gouvernance.org/es/analyse/fiche-analyse-450.html\#h2

Pásara, L. (2014). "La designación de jueces en la reforma de la justicia latinoamericana". Visita del 03 de Marzo de 2015, de Fundación para el Debido Proceso. Disponible en: http://dplfblog. com/2014/12/18/la-designacion-de-jueces-en-la-reforma-de-la-justicia-latinoamericana/

The Carter Center. (2008). Informe sobre la Asamblea Constituyente de la República del Ecuador. Visita del 3 de Abril de 2015, del Centro Carter. Disponible en: http://www.cartercenter.org/resources/pdfs/ peace/americas/Informe_Final_AC_-_Centro_Carter_distribuido. pdf 